\title{
FRAXA and FRAXE: the results of a five year survey
}

Sheila A Youings, Anna Murray, Nick Dennis, Sarah Ennis, Catherine Lewis, Nicky McKechnie, Michelle Pound, Andrea Sharrock, Patricia Jacobs

\begin{abstract}
We report the results of a five year survey of FRAXA and FRAXE mutations among boys aged 5 to 18 with special educational needs (SEN) related to learning disability. We tested their mothers using the $X$ chromosome not transmitted to the son as a control chromosome, and the $X$ chromosome inherited by the son to provide information on stability of transmission. We tested 3738 boys and 2968 mothers and found 20 FRAXA and one FRAXE full mutations among the boys and none among the mothers. This gives an estimated prevalence of full mutations in males of 1 in 5530 for FRAXA and 1 in 23423 for FRAXE.
\end{abstract}

We found an excess of intermediate and premutation alleles for both FRAXA and FRAXE. For FRAXA this was significant at the 0.001 level but the excess for FRAXE was significant only at the 0.03 level. We conclude that the excess of intermediate and premutation sized alleles for FRAXA may well be a contributing factor to the boys' mental impairment, while that for FRAXE may be a chance finding.

We studied approximately 3000 transmissions from mother to son and found five instabilities of FRAXA in the common or intermediate range and three instabilities of FRAXE in the intermediate range. Thus instabilities in trinucleotide repeat size for FRAXA and FRAXE are rare, especially among alleles in the common size range.

(F Med Genet 2000;37:415-421)

Keywords: FRAX syndromes; incidence; intermediate alleles; stability

In 1991 when the gene for fragile $\mathrm{X}$ was cloned, ${ }^{12}$ the prevalence of fragile $\mathrm{X}$ was accepted as approximately 1 in 1000 to 1 in $2600 .^{34}$ The frequency was based on population studies completed in the 1980s, when only a cytogenetic test was available for the diagnosis of fragile X. Following the discovery of the gene, some laboratories retested their families diagnosed as fragile $\mathrm{X}$ +ve and found a proportion of false positives. This was because (1) the test did not discriminate between FRAXA and other fragile sites in Xq27-28, and (2) a number of laboratories scored people as fragile $\mathrm{X}$ positive on the basis of a very small number of cells that appeared to have a fragile site, without having any suitable control data. ${ }^{56}$
Prompted by the discovery of the FMR1 gene, and before the present project, we carried out a pilot study ${ }^{7}$ using the Southern blotting method of FRAXA detection on blood samples. Following the pilot study, we initiated a five year research programme to test boys with special educational needs (SEN) for FRAXA and FRAXE. FRAXE was at that time a newly identified fragile site, ${ }^{8}$ shown to be the result of a polymorphic GCC repeat $\sim 600 \mathrm{~kb}$ distal to FRAXA, which appeared to have a similar expansion profile to FRAXA but was associated with a milder form of mental retardation. ${ }^{9}$

We published preliminary results after the first two years of the study, ${ }^{10}$ which detailed the aims of our research programme and some of our methodology. The purpose of the current paper is to report (1) the prevalence of FRAXA and FRAXE mutations in the total study population together with an estimate of the population frequency of full and premutations in both genes; (2) the distribution of allele sizes in the study population and in the control X chromosomes, with special reference to intermediate and premutation sized alleles; (3) the stability of transmission of repeat sizes from mother to son; (4) the segregation of $\mathrm{X}$ chromosomes among brothers in our population; and (5) the prevalence of boys with a $47, \mathrm{XXY}$ constitution detected in our population.

\section{Methods}

THE PROTOCOL

Our study was designed to test boys aged 5 to 18 years attending state schools in Wessex, a region in southern England with a population of approximately 2.3 million (table 1 ). The boys were selected for testing on two criteria: (1) they had SEN which were related to cognitive deficiencies with no medical diagnosis; (2) the parent/guardian was well aware that their child had SEN. The mothers of boys tested were invited to provide DNA samples to enable observation of triplet repeat stability in transmission and to use the $\mathrm{X}$ chromosome not transmitted to the son as our control. The samples collected were buccal cells obtained from mouth brushes. The community paediatricians or teachers in charge of special education selected the boys suitable for testing and the boys were only tested with parental/ guardian permission.

We contacted all schools in the state system; these ranged from special schools which only catered for children with SEN to regular schools. Because we were also testing for FRAXE mutations of which little is known
16 December 1999

Accepted for publication 11

January 2000 
except that they are associated with a mild phenotype, ${ }^{11}{ }^{12}$ we designed our survey to be inclusive rather than exclusive; thus, our target population ranged from boys with severe mental retardation to boys in the normal IQ range who needed extra help in some areas of learning.

Each sample was tested for FRAXA, FRAXE, and five flanking polymorphisms (DXS548, CA1, CA2, DXS1691, and DXS6687) and the number of trinucleotide repeats was divided into five classes (tables 2 and 3). If the boy or the mother or both had a result outside the common range an appointment was made to visit the family, a pedigree taken, and other family members identified who might have inherited the chromosome of interest. Samples were then requested from the relevant relatives. For clinical purposes, we treated any unmethylated allele with $>50$ repeats at FRAXA and $>40$ repeats at FRAXE as a premutation and families with results in the full or premutation range were seen by our clinical geneticist (NRD) who, as well as obtaining a family history and blood samples, carried out any necessary counselling. When a pre- or full mutation at FRAXA or E was confirmed, the family became part of our normal diagnostic service. During the course of our survey, we found a number of boys whose results suggested that they had two X chromosomes. These boys with suspected Klinefelter syndrome were all seen by our clinical geneticist and a blood sample obtained for cytogenetic confirmation.

\section{LABORATORY METHODS}

DNA was extracted and initial PCR reactions were carried out using fluorescently labelled oligonucleotide primers as previously described. ${ }^{10}$ Owing to inefficient amplification of larger FRAXA and FRAXE alleles with fluorescent primers, a conventional ${ }^{32} \mathrm{P}$ labelled PCR was occasionally required, particularly for

Table 1 Details of study population

\begin{tabular}{lccr}
\hline & $\begin{array}{l}\text { Special schools } \\
\text { population }\end{array}$ & $\begin{array}{l}\text { Regular schools } \\
\text { population }\end{array}$ & Total \\
\hline Total boys in schools contacted & 2707 & 133091 & 135798 \\
Total No of schools contacted & 50 & 759 & 809 \\
Total schools participating & 49 & 478 & 527 \\
\% of schools participating & 98 & 63 & 65 \\
Total boys in participating schools & 2632 & 79662 & 82294 \\
SEN boys offered test & 1696 & 3755 & 5451 \\
SEN boys tested & 1241 & 2497 & 3738 \\
\% uptake of test & 73 & 66 & 69 \\
Samples from mothers & 943 & 2025 & 2968 \\
\% mothers of boys tested & 76 & 81 & 79 \\
\hline
\end{tabular}

Table 2 Results for FRAXA

\begin{tabular}{lrlc}
\hline & Boys & Mothers' control $X$ \\
\hline FraxA failed & 6 & $(0.16 \%)$ & \\
FraxA minimum $=0-10$ & 1 & $(0.03 \%)$ & $36(1.2 \%)$ \\
FraxA common $=11-40$ & 3546 & $(95 \%)$ & $3(0.10 \%)$ \\
FraxA intermediate $=41-50$ & 141 & $(3.8 \%)$ & $2842(97 \%)$ \\
& 22 & $(0.6 \%)$ & $79(2.7 \%)$ \\
FraxA premutation $=61-200$ & $2^{\star}$ & $(0.05 \%)$ & $1(0.24 \%)$ \\
FraxA full = $>200$ & $20 \dagger$ & $(0.53 \%)$ & 0 \\
Total for FRAXA (successful) & 3732 & $(99.8 \%)$ & $2932(98.8 \%)$ \\
\hline
\end{tabular}

^One known before study.

$\dagger 17$ known before study. females who appeared homozygous. ${ }^{78}$ Females who had a single allele of 29,30 , or 31 repeats for FRAXA or 15, 16, or 18 for FRAXE were assumed to be homozygous. These repeat numbers are common, with an expected homozygosity frequency of greater than $1 \%$. A proportion of females assumed to be homozygous for common alleles were investigated further to ensure that expansions on the control chromosomes had not been missed. DNA was reamplified with unlabelled primers, separated on a denaturing polyacrylamide gel, and electroblotted to Zetaprobe membrane. Membranes were hybridised with a ${ }^{32} \mathrm{P}$ labelled $\mathrm{CGG}_{5}$ oligonucleotide probe, washed, and exposed to $x$ ray film. ${ }^{13}$ Sixty five percent of FRAXA homozygotes for 29, 30, or 31 repeats and $17 \%$ of FRAXE homozygotes for 15,16 , and 18 repeats selected at random were tested in this way. Females with a single allele other than these common ones were asked to provide a blood sample and a Southern blot was performed. DNA $(0.5 \mu \mathrm{g})$ was double digested with either EcoRI and BstZI (methylation sensitive) for the FRAXA protocol or HindIII and NotI (methylation sensitive) for FRAXE. Gels were Southern blotted and hybridised with ${ }^{32} \mathrm{P}$ labelled probes, StB12.3 for FRAXA, ${ }^{14}$ or OxE20 for FRAXE. ${ }^{8}$ Southern blotting was also carried out on males for whom we failed to obtain a PCR result for FRAXA or FRAXE and on boys with a repeat number greater than 50 for FRAXA, to check for mosaicism of a larger expansion.

\section{Results}

STUDY POPULATION

Details of the total study population are given in table 1 . There are 809 state schools in our area and 527 participated. We held clinics in 360 schools while 167 had no boys suitable for testing. Of the 282 non-participating schools, 42 declined to join the survey and 240 did not reply. There was a total of 135798 boys aged 5 to 18 in the 809 eligible schools, while in the 527 schools which participated there were 82294 boys in the appropriate age range. The test was offered to 5451 boys of whom 3738 were tested, an uptake of $69 \%$. Of the 1713 boys not tested, 175 refused, 37 letters were returned, 68 agreed to testing but were absent on clinic day, and 1433 did not reply to either the original or the follow up letter. We received 2968 samples from mothers of the boys tested, an uptake of $79 \%$. A further 244 mothers agreed to give samples but failed to return the sample pack. The remaining 527 mothers either refused or were not available for testing.

Among the 809 eligible schools, 50 were special schools in which all the pupils had either moderate learning difficulties (MLD), severe learning difficulties (SLD), physical difficulties (PD), or emotional and behavioural disorders (EBD). One third of the boys tested in this survey attended special schools (table 1) and the remaining two thirds attended regular state schools. Forty nine of the special schools participated and we held clinics in 46 . Of those not visited, three had no boys suitable for testing (two schools for EBD boys and one for boys 
with PD) and one school (MLD) did not reply. The high uptake among the special schools is presumably a reflection of a perception that there is more likely to be a medical explanation for the learning difficulties associated with pupils at the lower end of the academic scale.

PREVALENCE OF FULL AND PREMUTATIONS

In the study population

Alleles for FRAXA and FRAXE were divided into five classes: minimal, common, intermediate, premutation, and full mutation (tables 2 and 3) based on size and methylation status. As can be seen from table 2 we found 20 full FRAXA mutations and two premutations with repeat numbers over 60 among the tested boys, and of these 17 full mutations and one premutation were already known to us through the diagnostic service. Among the 20 full mutations, five were mosaics, and of these, two were methylation mosaics while three had both preand full mutation sized alleles. Among the mothers' control chromosomes we observed no full mutations and one premutation. All the full mutations were found in boys attending special schools. As can be seen from table 3, we found a single full FRAXE mutation and two premutations among the tested boys and of these the full mutation was already known to us through the diagnostic service and was attending a special school. No full or premutation sized alleles were found among the mothers' control chromosomes.

When a boy, already known to us as having a FRAXA or FRAXE mutation, appeared on a school list for testing, we did not contact the boy or his family again, but included him on our list of tested subjects. Clearly this may have inflated the number of full mutations in our tested population as a proportion of these subjects might have refused to be tested had we approached them in the absence of a diagnosis. However, we have attempted to allow for this possible source of bias when calculating the population frequency of full FRAXA and FRAXE mutations.

The failure rate of tested samples from the boys was $0.16 \%$ (six boys) at FRAXA and $0.2 \%$ (seven boys) at FRAXE (tables 2 and 3 ). Of the six boys for whom we failed to obtain a result at FRAXA, the mothers of three were heterozygous for two common alleles and in two out of the three remaining cases the DNA failed for all tested loci. Therefore, for five boys the most likely explanation for failure was insufficient or degraded DNA. We are concerned about the one remaining case, for whom the FRAXA result is unresolved,

Table 3 Results for FRAXE

\begin{tabular}{lrlc}
\hline & Boys & Mothers' control $X$ \\
\hline FraxE failed & 7 & $(0.2 \%)$ & \\
FraxE minimum $=0-10$ & 31 & $(0.83 \%)$ & $32(1.1 \%)$ \\
FraxE common $=11-30$ & 3656 & $(98 \%)$ & $21(0.71 \%)$ \\
FraxE intermediate $=31-40$ & 37 & $(1.0 \%)$ & $2896(98 \%)$ \\
& 4 & $(0.11 \%)$ & $18(0.61 \%)$ \\
FraxE premutation $=61-200$ & 2 & $(0.05 \%)$ & $1(0.03 \%)$ \\
FraxE full = >200 & $1^{\star}(0.03 \%)$ & 0 \\
Total for FRAXE (successful) & 3731 & $(99 \%)$ & $2936(99 \%)$ \\
\hline
\end{tabular}

^One known before study. because we obtained results for all markers except FRAXA. Therefore, he could be either a pre- or full mutation that we did not detect using PCR methods. However, we have been unable to obtain a repeat sample from this boy. For the seven boys who failed at FRAXE, we obtained heterozygous results in the normal range for five mothers and the two remaining cases failed for all markers, so the most likely explanation for failure in all seven cases is technical. The failure rate for the mothers was $1.2 \%$ at FRAXA and $1.1 \%$ at FRAXE. The higher failure rate among the mothers was probably because they took their own samples, whereas the samples from boys were obtained by an experienced genetic nurse.

\section{In the total population}

There were three groups of boys in the population who were not tested, and who were at different risks of having a full mutation: (1) eligible boys in special schools, (2) eligible boys in regular schools, and (3) boys who were not offered the test. Although no FRAXA or FRAXE subject with a full mutation is known to the diagnostic laboratory among boys not eligible for the test, there may be one or more among boys not yet recognised as having SEN or recognised but not tested. In the absence of a generally accepted method to allow for these contingencies, we used the Poisson distribution $^{15}$ to estimate a $95 \%$ confidence limit for the number of cases missed in those two groups as $m=-\ln \quad 0.05=3$. Within the FRAXA group with 20 cases, the $95 \%$ Poisson confidence interval is $12.22-30.89$. Summing the two risk groups and dividing by the school population, a conservative interval is $1 / 8922$ to $1 / 4007$ with midpoint $1 / 5530$. An alternative calculation that neglects sampling error in the observed number is $23 / 135798=1 / 5094$. If, in addition, the possibility of missed cases is ignored, the estimate is $1 / 6790$. Both are well within the Poisson confidence interval. A similar calculation for FRAXE full mutations among males is $1 / 23423$ (confidence interval $1 / 44887-1 / 15$ 486)

If we assume that premutation sized alleles have no phenotypic effect with respect to intellectual performance, the frequency in the studied population, both boys and the mothers' control chromosome, is the population prevalence. We tested a total of 6664 chromosomes for FRAXA and found three to have a premutation with between 61 and 200 repeats, a frequency of 1 in 2221. However, if under a less stringent model we regard alleles of 51 to 200 repeats as premutations, the frequency becomes 1 in 208. As the definition of a premutation is arbitrary, it is not possible to determine its population prevalence with accuracy. If we assume that premutation and intermediate alleles have a deleterious effect on intelligence (see below), the prevalence is given by the control chromosomes alone, namely 1 in 2932 for alleles over 60 and 1 in 418 for alleles greater than 50 .

Similarly for FRAXE, we tested a total of 6667 chromosomes and found two to have a premutation with repeat size over 60 , a 
frequency of 1 in 3334, and seven to have a repeat size over 40, a frequency of 1 in 952 . If we assume premutation and intermediate alleles have an effect on intelligence, the prevalence for alleles over 60 repeats is extremely low while that for alleles over 40 repeats is 1 in 2936.

FREQUENCY OF INTERMEDIATE ALLELES

The distribution of allele sizes is given in tables 2 and 3 . When we analysed our data after the first two years of the study we were surprised to find a significant excess of intermediate and premutation sized alleles for both FRAXA and FRAXE among the boys by comparison with the controls. ${ }^{10}$ We have now analysed the frequency of intermediate alleles for FRAXA and FRAXE in the whole population. For this analysis, all XXY boys and their mothers, as well as one XXX mother, were removed from the samples.

If we treat our study population as two separate cohorts, the first two years when we initially found the unexpected result ${ }^{10}$ compared to the final three years which can be regarded as an independent population, we see from table 4 that the excess of intermediate and premutation alleles is significant in both cohorts for FRAXA, lending independent evidence to the hypothesis that intermediate and premutation alleles have an effect on intellectual ability. For FRAXE, the result is inconclusive as significance for the second sample has diminished. However, the pooled data remain significant. The excess of intermediates for FRAXA was similar in the whole study population and in the special schools subpopulation, suggesting that the effect of intermediate alleles is apparent across a wide range of learning difficulties.
STABILITY

We tested 2932 mother to boy transmissions and found only eight changes in transmission in the common and intermediate range, five at FRAXA and three at FRAXE (table 5). In every case the haplotype was known from family studies. We have also considered the transmissions from premutations. There were 16 for FRAXA (table 5), the remaining six cases being from mothers with a full mutation. At FRAXE there were two transmissions from mothers with premutations, and none from full mutations.

\section{BROTHERS}

Among the survey boys, we tested 160 pairs of brothers for whom we had maternal data, which included 15 pairs of twins. All twins were excluded except for two sets who were identical for all loci tested and had a brother; these twins versus the singleton brother were counted as one pair. This resulted in $147 \mathrm{sib}$ pairs eligible for analysis. Each pair was examined in order to determine if among these brothers with SEN there was a tendency to inherit the same maternal haplotype as defined by the tested polymorphic markers detailed in the Methods section. However, no significant tendency was seen, as 80 pairs of brothers inherited the same maternal haplotype and 67 pairs inherited different maternal haplotypes for the six loci tested $\left(\chi^{2}=1.15\right)$. These results suggest there is not a gene closely linked to the Xq27.3 region which contributes significantly to the special educational needs of the brothers in our population.

KLINEFELTER SYNDROME

During the survey we diagnosed 15 boys, including one pair of twins, who had two alle-

Table 4 Intermediate and premutation alleles among boys and controls

\begin{tabular}{|c|c|c|c|c|c|c|c|c|}
\hline & \multirow{2}{*}{$\begin{array}{l}\text { Allele } \\
\text { size }\end{array}$} & \multirow[b]{2}{*}{ Sample 1} & \multirow[b]{2}{*}{ Sample 2} & \multirow[b]{2}{*}{ Total } & \multicolumn{4}{|c|}{ Chi-squared values } \\
\hline & & & & & Sample 1 & Sample 2 & Total & Heterogeneity \\
\hline \multicolumn{9}{|l|}{ FRAXA } \\
\hline Cases & $\begin{array}{l}\mathrm{M}+\mathrm{C} \\
\mathrm{I}+\mathrm{P}\end{array}$ & $\begin{array}{r}1018 \\
39\end{array}$ & $\begin{array}{r}2517 \\
125\end{array}$ & $\begin{array}{r}3535 \\
164\end{array}$ & $\begin{array}{l}5.731 \\
(p=0.017)\end{array}$ & $\begin{array}{l}6.413 \\
(p=0.011)\end{array}$ & $\begin{array}{l}11.082 \\
(p=0.001)\end{array}$ & 1.062 \\
\hline Controls & $\begin{array}{l}\mathrm{M}+\mathrm{C} \\
\mathrm{I}+\mathrm{P}\end{array}$ & $\begin{array}{r}793 \\
15\end{array}$ & $\begin{array}{r}2035 \\
69\end{array}$ & $\begin{array}{r}2828 \\
84\end{array}$ & & & & \\
\hline \multicolumn{9}{|l|}{ FRAXE } \\
\hline Cases & $\begin{array}{l}\mathrm{M}+\mathrm{C} \\
\mathrm{I}+\mathrm{P}\end{array}$ & $\begin{array}{r}1048 \\
13\end{array}$ & $\begin{array}{r}2621 \\
30\end{array}$ & $\begin{array}{r}3669 \\
43\end{array}$ & $\begin{array}{l}6.339 \\
(p=0.012)\end{array}$ & $\begin{array}{l}1.281 \\
(p=0.258)\end{array}$ & $\begin{array}{c}4.671 \\
(\mathrm{p}=0.031)\end{array}$ & 2.749 \\
\hline Controls & $\begin{array}{l}\mathrm{M}+\mathrm{C} \\
\mathrm{I}+\mathrm{P}\end{array}$ & $\begin{array}{r}806 \\
2\end{array}$ & $\begin{array}{r}2088 \\
17\end{array}$ & $\begin{array}{r}2894 \\
19\end{array}$ & & & & \\
\hline
\end{tabular}

Table 5 Instabilities in transmission from mother to son

\begin{tabular}{|c|c|c|c|}
\hline \multicolumn{3}{|l|}{$F R A X A$} & \multirow{2}{*}{$\begin{array}{l}F R A X E \\
37 \text { to } 27 / 37\end{array}$} \\
\hline 34 to 37 & 68 to $\mathrm{F}$ & 100 to $\mathrm{F}$ & \\
\hline 43 to 42 & 76 to $\mathrm{F}$ & $\dagger 100$ to $\mathrm{P} / \mathrm{F}$ & 60 to $58 \ddagger$ \\
\hline 45 to 47 & 78 to $\mathrm{F}$ & $\dagger 102$ to $\mathrm{P} / \mathrm{F}$ & 60 to $65 \ddagger$ \\
\hline 47 to 48 & 82 to $104 / \mathrm{F}$ & +102 to $F$ & 66 to 87 \\
\hline 53 to 54 & 83 to $\mathrm{F}$ & $\dagger 160$ to $\mathrm{F}$ & $\dagger 100$ to $\mathrm{F}$ \\
\hline 71 to 74 & 88 to $\mathrm{F}$ & $\dagger 160$ to $F$ & \\
\hline$\star \mathrm{P}$ to 150 & 95 to $\mathrm{F}$ & $\dagger 180$ to $\mathrm{P} / \mathrm{F}$ & \\
\hline \multicolumn{4}{|c|}{ Instabilities in common and intermediate range } \\
\hline \multicolumn{2}{|c|}{ Common range } & \multicolumn{2}{|c|}{ Intermediate range } \\
\hline \multirow{2}{*}{\multicolumn{2}{|c|}{$\begin{array}{l}\text { FRAXA }=2869 \text { transmissions }=1 \text { mutation }=0.03 \% \\
\text { FRAXE }=2972 \text { transmissions }=0 \text { mutations }=0.00 \%\end{array}$}} & \multicolumn{2}{|c|}{ FRAXA $=151$ transmissions $=4$ mutations $=2.64 \%$} \\
\hline & FRAXE $=2972$ transmissions $=0$ mutations $=0.00 \%$ & \multicolumn{2}{|c|}{ FRAXE $=82$ transmissions $=3$ mutations $=3.6 \%$} \\
\hline
\end{tabular}

${ }^{\star}$ Mother not tested in this laboratory.

tEstimates from Southern blot sizes.

$\ddagger$ Same mother. 
les at a number of the $\mathrm{X}$ loci we tested. In every case a blood sample was obtained and a 47,XXY karyotype found on standard cytogenetic investigation. Six of the boys had inherited both maternal alleles suggesting a maternal origin for both $\mathrm{X}$ chromosomes, while seven, including the twins, had inherited one maternal allele and at some loci an allele that was not present in the mother, so must be paternal in origin. In two patients there was no maternal sample available, so the origin of the additional $\mathrm{X}$ is not known. Klinefelter syndrome is present in 1 in 1000 newborn males and is associated with phenotypic abnormalities including a reduction in mean IQ. ${ }^{16}$ As a result it is found with increased frequency among males with mental impairment, although its frequency in a population of boys with SEN is not known. We detected 15 cases in the 3738 boys studied $(0.4 \%)$, but our methodology is likely to detect only a proportion of $47, \mathrm{XXY}$ males. It is known that approximately $50 \%$ are of maternal and $50 \%$ of paternal origin. ${ }^{17}$ We tested six highly polymorphic loci in Xq27-28 and so should have detected most of the paternal cases. We are likely to have missed the Klinefelter cases who are homozygous for the markers tested, either as a result of a maternal meiotic nondisjunctional error associated with recombination or a postzygotic mitotic error. Crawford et $a l,{ }^{18}$ in a similar survey, detected seven $47, \mathrm{XXY}$ males among 1979 tested (0.35\%), a frequency very similar to that seen by us. In contrast to our observation of only three previously undiagnosed full FRAXA mutations and no previously undiagnosed FRAXE mutations among the 3738 boys tested, 13 of the 15 with Klinefelter syndrome were previously undiagnosed. While we are only likely to have detected a proportion of such cases, it was a somewhat unexpected bonus, as it provided an explanation for the SEN in these boys.

\section{Discussion}

Since the introduction of a molecular technique for the diagnosis of FRAXA expansions, there have been a number of studies aimed at determining the incidence of full mutations in the population. The great majority of these were based on surveys of mentally retarded males and subsequent extrapolation to give a population incidence of FRAXA full mutations. Most are based on surveys of between 200 and 2000 subjects and estimate a population frequency of approximately 1 in $4000 .^{561819}$ These include a molecular reappraisal of the cytogenetic surveys of Turner et $a l^{4}$ and Webb et $a l^{3}{ }^{3}$ and in both cases the frequencies given by cytogenetic studies were reduced substantially.

Recently de Vries et $a l^{20}$ published a large survey in the Dutch population in which they found a prevalence of approximately 1 in 6000 full FRAXA mutations, a figure very similar to the prevalence of 1 in 5500 in our survey, while Crawford $e t ~ a l^{18}$ in a somewhat smaller survey found a prevalence of 1 in 3460 for the general white male population and 1 in 4048 for the African-American male population. However, the $95 \%$ confidence intervals for these estimates include the figures estimated by de Vries et $a l^{20}$ and by ourselves.

In any survey that relies on informed consent, it is always possible that because of a personality trait associated with the genotype under study, the condition occurs with a higher frequency among those who did not agree to participate than among those who did. The reverse situation could also occur. This potential source of bias is difficult to detect and thus impossible to correct. However, it seems reasonable to suppose, based on the weight of evidence currently available, that the population prevalence of FRAXA full mutations is between 1 in 4000 and 1 in 6000 .

It is of interest that in our survey we found only three of the 20 FRAXA full mutations to be previously undiagnosed cases, while the remaining 17 were already known to us. This led us to conclude that in our jurisdiction, which has had excellent diagnostic services for some 30 years, the great majority of fragile $\mathrm{X}$ full mutations have already been diagnosed. This contrasts with the survey of de Vries et $a l^{20}$ in which $50 \%$ of full mutations were previously undiagnosed.

An estimate for FRAXE prevalence of 1 in 50000 has been suggested. ${ }^{21}$ However, this was not based on direct testing. There are only two large population based surveys in which an estimate of the prevalence of FRAXE full mutations can be based, namely that of Crawford $e t a l^{18}$ and the present report, and it is clear that it is extremely rare. Crawford et $a l^{18}$ found none among 1866 subjects while we found only 1 among 3731 boys with SEN, giving an estimated population prevalence of 1 in 23 500. Numerous other small surveys of mentally impaired subjects have been reported $^{1922-26}$ and in a total of 3769 tested subjects only two had FRAXE full mutations. Because of the rarity of FRAXE full and premutations, there is no clear description of the associated phenotype. While it is generally agreed that expansions are associated with mild mental retardation in the absence of physical abnormality, the relationship between the retardation and the expansions is not at all clear.

We reported an unexpected excess of intermediate and premutation alleles among the boys in our survey for both FRAXA and FRAXE in the first two years of the study. ${ }^{10} \mathrm{We}$ continued to show this excess for FRAXA in the last three years of the survey and over the whole study the excess is significant at the 0.001 level. In contrast, the excess shown for FRAXE in the first two years was not seen in the last three years of the survey, although the excess overall is still significant but only at the 0.03 level. As our controls were the X chromosomes of the mothers that were not transmitted to the SEN sons, one formal explanation for our observations would be the preferential transmission of the larger maternal allele to the son. We tested this and found no evidence for any preferential transmission either in the survey population or among the families in which intermediate, pre-, or full mutations were 
segregating. ${ }^{27}$ Thus we conclude that the excess of intermediates and premutations for FRAXA among the boys with SEN may be real and that intermediate and premutation alleles have a deleterious effect on intellectual performance or behaviour or both. There is now a well established phenotypic effect of premutation sized alleles, namely premature ovarian failure, ${ }^{28}$ so our observation of a second biological effect of large unmethylated repeats is not without precedent. Unfortunately, we are unable to obtain phenotypic information on the boys with intermediate alleles and therefore are unable at present to define their phenotype.

Since we first published our observations of an excess of intermediate and premutation sized alleles among the boys with SEN, at least four studies have addressed the same problem. In three studies which included White American, Black American, Cypriot, Canadian, and French cases, ${ }^{181929}$ no increased frequency of intermediate or premutation alleles was found among retarded males by comparison with the appropriate controls. In the remaining study, carried out in Brazil on relatively small numbers of patients and controls, there was an increased frequency of intermediate and premutation alleles among the impaired males, but this did not reach statistical significance. ${ }^{30}$ In the absence of phenotypic data from our population, it is impossible to know whether the differences among studies are the result of different ascertainment criteria or attributable to some other cause. If our results on FRAXA are valid they suggest that the contribution to mental impairment of intermediate and premutation alleles is greater than that of full mutations. While the attributable penetrance of mental retardation among full mutations is 1 and that for intermediate/premutations is much less, the number of the latter is much greater. ${ }^{27}$

As we were particularly interested in the stability of transmission of the FRAXA and FRAXE repeats from mother to son, we separated PCR products on an ABI 377 sequencer so that even instabilities of one repeat size could be reliably detected. Among 3020 transmissions for FRAXA we found 21 mutations, of which only one was in the common range and four in the intermediate range. Thus, transmissions of FRAXA repeats, at least from females, seem remarkably stable, although instabilities are approximately 90 times more frequent in the intermediate than the common range. Among 3054 transmissions of FRAXE we found five mutations, three in the intermediate range and two in the premutation range, again showing how stable such transmissions are, especially in the common range.

In conclusion, it is of interest that all full mutations detected by us were in boys attending special schools, although they formed only one third of all boys tested. Thus, it is clear that in our population FRAXA and FRAXE full mutations are extremely rare among boys with SEN who attend ordinary schools. Our data suggest that population screening for FRAXA and FRAXE would not be cost effective in a population which has been in receipt of comprehensive genetic services for a considerable period. However, in a population in which a significant proportion of FRAXA mutations are undetected, it could be cost effective to screen a population of boys in special schools, selected on the basis of phenotypic features associated with the FRAXA syndrome, as this is known to make such screening considerably more effective. ${ }^{31}$

We thank the Wellcome Trust for funding this research and Dr James Macpherson and Professor Newton Morton for their stimulating discussions and helpful suggestions. We are very grateful to the community paediatricians and SEN teachers of Southampton, Winchester, East and West Dorset, Portsmouth, and Basingstoke for their valuable help. We also thank the Education Departments in each of the districts for supporting this work and for supplying relevant data. Last but not least we thank the boys and their families for their cooperation.

1 Verkerk AJMH, Pieretti M, Sutcliffe JS, et al. Identification of a gene (FMR-1) containing a CGG repeat coincident of a gene (FMR-1) containing a CGG repeat coincident
with a breakpoint cluster region exhibiting length variation in fragile X syndrome. Cell 1991;65:905-14.

2 Yu S, Pritchard M, Kremer E, et al. Fragile X genotype characterized by an unstable region of DNA. Science 1991; 252:1179-81

3 Webb TP, Bundey S, Thake A, Todd J. The frequency of the fragile X chromosome among schoolchildren in Coventry. 7 Med Genet 1986;23:396-9.

4 Turner G, Robinson H, Laing S, Purvis-Smith S. Preventive screening for the fragile X syndrome. N Engl f Med 1986; 315:607-9.

5 Turner G, Webb T, Wake S, Robinson H. Prevalence of fragile X syndrome. Am F Med Genet 1996;64:196-8.

6 Morton JE, Bundey S, Webb TP, Macdonald F, Rindl PM, Bullock S. Fragile X syndrome is less common than previously estimated. F Med Genet 1997;34:1-6.

7 Jacobs PA, Bullman H, Macpherson J, et al. Population studies of the fragile $(\mathrm{X})$ : a molecular approach. $\mathcal{f} \mathrm{Med}$ Genet 1993;30:454-9.

8 Knight SJL, Flannery AV, Hirst MC, et al. Trinucleotide repeat amplification and hypermethylation of a $\mathrm{CpG}$ island in FRAXE mental retardation. Cell 1993;74:127-34.

9 Knight SJL, Voelckel MA, Hirst MC, Flannery AV, Moncla A, Davies KE. Triplet repeat expansion at the FRAXE locus and X-linked mild mental handicap. Am f Hum Genet 1994;55:81-6.

10 Murray A, Youings S, Dennis N, et al. Population screening at the FRAXA and FRAXE loci: molecular analyses of boys with learning difficulties and their mothers. Hum Mol Genet 1996;5:727-35.

11 Mulley JC, Yu S, Loesch DZ, et al. FRAXE and mental retardation. F Med Genet 1995;32:162-9.

12 Abrams MT, Doheny KF, Mazzocco MMM, et al. Cognitive, behavioural, and neuroanatomical assessment of Cognitive, behavioural, and neuroanatomical assessment of Genet 1997;74:73-82.

13 Brown WT, Houck GE, Jeziorowska A, et al. Rapid fragile X carrier screening and prenatal diagnosis using a nonradiocarrier screening and prenatal diagnosis using

14 Rousseau F, Heitz D, Biancalana V, et al. Direct diagnosis by DNA analysis of the fragile $\mathrm{X}$ syndrome of mental retardation. N Engl f Med 1991;325:1673-81.

15 Feller W. On the normal approximation to the binomial distribution. Ann Math Stat 1945;16:319-29.

16 Hamerton JL, Canning N, Ray M, Smith S. A cytogenetic survey of 14,069 newborn infants. Clin Genet 1975;8:22345 .

17 Macdonald M, Hassold T, Harvey J, Wang LH, Morton $\mathrm{NE}$, Jacobs P. The origin of $47, \mathrm{XXY}$ and $47, \mathrm{XXX}$ aneuploidy: heterogeneous mechanisms and role of aberrant recombination. Hum Mol Genet 1994;3:1365-71.

18 Crawford DC, Meadows KL, Newman JL, et al. Prevalence and phenotype consequence of FRAXA and FRAXE alleles in a large, ethnically diverse, special education-needs les in a large, ethnically diverse, special education
population. Am f Hum Genet 1999;64:495-508.

19 Patsalis PC, Sismani C, Hettinger JA, et al. Molecular screening of fragile X (FRAXA) and FRAXE mental retardation syndromes in the Hellenic population of Greece and dation syndromes in the Hellenic population of Greece and
Cyprus: incidence, genetic variation, and stability. Am $\mathcal{F}$

20 de Vries BBA, van den Ouweland AMW, Mohkamsing S, et al. Screening and diagnosis for the fragile $\mathrm{X}$ syndrome among the mentally retarded: an epidemiological and psychological survey. Am f Hum Genet 1997;61:660-8.

21 Brown WT. The FRAXE syndrome: is it time for routine screening? Am F Hum Genet 1996;58:903-5.

22 Holden JJA, JulienInalsingh $\mathrm{C}$, Chalifoux $\mathrm{M}$, et al. Trinucleotide repeat expansion in the FRAXE locus is not common among institutionalized individuals with nonspecific developmental disabilities. Am 7 Med Genet 1996;64:420-4.

23 Allingham-Hawkins DJ, Ray PN. FRAXE expansion is not a common etiological factor among developmentally delayed males. Am f Hum Genet 1995;56:72-7.

24 Knight SJL, Ritchie RJ, Chakrabarti L, et al. A study of FRAXE in mentally retarded individuals referred for frag- 
ile X syndrome (FRAXA) testing in the United Kingdom. Am $\mathcal{F}$ Hum Genet 1996;58:906-14.

25 Zhong N, Ju W, Curle; D, et al. A survey of FRAXE allele 19.

26 Holinski-Feder E, ChahrokhZadeh S, Jedele KB, Meindl A Steinbach P, Wohrle D. FRAXE testing. Am f Hum Genet 1996;59:1168-9.

27 Teague JW, Morton NE, Dennis N, et al. FRAXA and FRAXE: evidence against segregation distortion and for an effect of intermediate alleles on learning disability. Proc Natl Acad Sci USA 1998;95:719-24.

28 Allingham-Hawkins DJ, Babul-Hirji R, Chitayat D, et al. Fragile $\mathrm{X}$ premutation is a significant risk factor for prema- ture ovarian failure. The international collaborative POF in fragile X study - preliminary data. Am 7 Med Genet $1999 ; 83: 322-5$

29 Mornet E, Chateau C, Simon-Bouy B, Serre JL. The intermediate alleles of the fragile X CGG repeat in patients with mental retardation. Clin Genet 1998;53:200-2.

30 Haddad LA, Aguiar MJB, Costa SS, Mingroni-Netto RC, Vianna-Morgante AM, Pena SDJ. Fully mutated and grayone FRAXA alleles in Brazilian mentally retarded boys. Am F Med Genet 1999;84:198-204.

31 de Vries BBA, Mohkamsing S, van den Ouweland AMW, et al. Screening for the fragile $\mathrm{X}$ syndrome among the mentally retarded: a clinical study. $\mathcal{F}$ Med Genet 1999;36: $467-70$. 